Quebec Cooperative Study of

Friedreich's Ataxia

\title{
Taurine in Cerebrospinal Fluid in Friedreich's Ataxia
}

\author{
B. LEMIEUX, R. GIGUERE, A. BARBEAU, S. MELANCON AND D. SHAPCOTT
}

SUMMARY: In a previous study we reported low values of taurine and aspartic acid in the CSF of patients with Friedreich's ataxia, when the results were compared to the literature. Further studies have revealed that unforetold difficulties with the advertised methodology of sequential multi-sample amino acid analysis were responsible for low values in the determination of these

RÉSUMÉ: Lors d'une étude antérieure nous avions rapporté des valeurs basses de taurine et d'acide aspartique dans le $L C R$ de patients souffrant d'ataxie de Friedreich, lorsque nos résultats étaient comparés à ceux de la littérature. Des études subséquentes révèlent maintenant qu'il existait des difficultés imprévaes dans l'application de la méthode recommandée, lorsque l'on emploi l'analyse séquentielle à plusieurs échantillons des acides aminés et que ces difficultés étaient responsables des valeurs basses obtenues pour ces deux acides aminés dans les volumes réduits two amino acids in the small volumes necessary for CSF. A corrected method is presented. With the latter method the differences disappear for CSF taurine and aspartic acid, but they remain valid for the previously reported blood and urine values in Friedreich's ataxia. $G A B A$ levels are also normal in Friedreich's ataxia CSF.

disponibles pour l'analyse du LCR. Une nouvelle méthode corrigée est maintenant proposée. Avec cette méthode modifiée la différence entre les ataxiques et les contrôles dans le LCR disparaît pour la taurine et l'acide aspartique, mais il n'y a aucune modification des valeurs publiées dans les résultats concernant les acides aminés sanguins et urinaires chez les victimes d'ataxie de Friedreich. Les niveaux de GABA sont également normaux dans le LCR de patients ataxiques.
In Phase One of the Quebec Cooperative Study of Friedreich's Ataxia we reported preliminary findings for the free amino acids in the cerebrospinal fluid (C.S.F.) of 15 patients with typical Friedreich's ataxia (group la) (Lemieux et al., 1976) and compared them to results from the literature for control C.S.F. (Scriver and Rosenberg, 1973; Plum, 1974). Our values for taurine were lower than the published control values. However, subsequent analysis of six samples of C.S.F. from normal subjects by our technique also showed low taurine levels. In view of the possible role of taurine in the pathophysiology of Friedreich's ataxia, we extended our work to determine the cause of the discrepancy between our control values and those reported in the literature. We report the results of amino acid analysis in 14 patients with typical Friedreich's ataxia, based on a modification of the method originally recommended for the determination of amino acids, using the Sequential Multi-Sample Amino Acid Analysis (operation manual for the technician TSM System. Technical publication No. TA-1-0233-10, 1973).

Except for the conclusions drawn from the previous results of taurine and aspartic acid levels in C.S.F., we will not discuss the other amino acids in C.S.F. or other physiological fluids, as these values were not changed by the technical modifications to be described

\section{METHOD AND MATERIALS}

(a) Patients:

This study was carried out on the CSF of patients previously studied in Phase One, except for two new 
patients. All 14 patients have typical Friedreich's ataxia (group Ia). However, on the 12 original patients, we obtained 5 new CSF samples and 7 were the original test samples previously analysed which had been stored at $-20^{\circ} \mathrm{C}$ for less than one year.

\section{(b) Controls:}

First group (Original controls): CSF was obtained from six males (age 12 to 17) who had undergone lumbar puncture as part of a diagnostic study of their illness or as part of a study with pneumoencephalogram.
Second group (New controls): Using the same selection criteria, CSF from 3 males and 4 females of matched age were chosen for amino acid analysis. In all these control samples the biochemical parameters (protein, glucose, etc.) were within normal limits.

\section{(c) Technique:}

As the decrease in amino acid levels in CSF, in both controls and Friedreich's ataxia patients, was observed only for the first 2 or 3 amino acids eluted from the acidic neutral column, it was evident that we were dealing with a technical problem in-

TABLE I

AMDUNIS OF SULFOSALICYLIC ACID (SSA) $\mathrm{mg} / \mathrm{ml}$ OF CFS USED BY DIFFERENT

AUTHORS AND THEIR VALUES FOR TAURINE

$\underline{\text { AUTHORS }}$

DEPROTETNISATION

TECHNIQUE

1. IAKKKE and TEELLKEN

108 SSA $(7.1 \mathrm{v} / \mathrm{V})$

$4 \mathrm{ml}$ of $3.758 \mathrm{SSA}$

per $\mathrm{ml}$ of CSF

(1974)

3. LEMIEUX et al. (1976)

4. LIAPPIS et al. (1977)

5. DICKINSON and HAMILTON (1966)

6. GJESING et al. (1972)

7. SZIIAGYL et al. (1974)

8. PERRY et al. (1975)

9. VAN SANDE et al. (1970) herent in the type of apparatus used in the ion exchange chromatography of amino acids. This loss of amino acids could be due either to the deproteinisation technique, or more likely to the incomplete adsorption of sample to the cartridge. Two sets of experiments were designed to investigate this problem.

First experiment: (SSA (Sulfosalicylic Acid) deproteinisation of CSF). Different concentrations of SSA varying from 5 to $150 \mathrm{mg} / \mathrm{ml}$ CSF were used with and without previous lyophylisation of the sample and complete analysis of both standard solutions and CSF samples were carried out according to the previous method.

Second experiment: (Amino acid adsorption on the cartridge). A study of the volume of sample in relation to adsorption to the cartridge was made in order to determine the degree of retention of amino acids by the resin (Chromobead C-3). Solutions containing 10 nanomoles of a mixture of amino acids in a volume of 25,50 or $100 \mu 1$ (with or without lyophylisation and reconstitution to the original volume) and also $200 \mu \mathrm{l}$ were added to the sample cartridges in the normal manner and analysed.

\section{Current method for CSF analysis}

In order to reduce to a minimum the volume of CSF for better adsorption on the cartridge, we have chosen the process of lyophylisation. CSF was collected by lumbar puncture (usually performed in the morning when the subjects were fasting) with a simultaneous plasma sample. $500 \mu \mathrm{l}$ of CSF was deproteinized with $500 \mu \mathrm{l}$ of $9 \%$ SSA, with 10 nanomoles of norleucine added as an internal standard. After centrifugation for 10 minutes at 6,000 r.p.m., the supernatant was lyophylized, and the residue was then dissolved in $\mathbf{2 0 0}$ $\mu l$ of sample buffer. The total volume $(200 \mu \mathrm{l})$ was added to the cartridge in the usual manner. The concentration of each of the ninhydrin positive substances is expressed in $\mu \mathrm{M} /$ liter of CSF by comparison to a standard mixture of amino acids containing 10 nanomoles in a volume of $200 \mu \mathrm{l}$. 


\section{RESULTS}

1) SSA Deproteinisation:

Different concentrations of SSA did not alter the recovery from standard amino acid solutions added to cartridges, either for the first amino acids eluted, such as taurine, or for all other amino acids from the acidic or basic column. A review of the quantity of SSA used by different investigators for the deproteinisation of CSF is shown in Table I with the values for taurine using our new method.

\section{2) Adsorption on the cartridge:}

A fixed amount (10 nanomoles) of the first two amino acids eluted from the acidic/neutral column (cysteic acid and taurine) was dissolved in different volumes of sample buffer. The recorder peak areas obtained are shown on Table II. The loss of these amino acids is proportional to the volume of sample solution. There is no statistical difference in the recovery for solutions which had been lyophylised and reconstituted to the original volume.

\section{New method of CSF amino acid determination}

Table III shows the result, for control and Friedreich's ataxia patient groups of 23 amino acids analysed by the original and the new methods. There are no statistical differences with either methods for any amino acids. Taurine and aspartic acid in both our controls and Friedreich's ataxia patients were low with the original method, although not different from each other. The values are now higher, but are still not different from each other.

Table IV shows the individual values for taurine and aspartic acid in individual patients by the new method, including their plasma/CSF ratio. The mean and standard deviations are compared with current data from the literature. The apparent slight increase of taurine concentrations in CSF in Friedreich's ataxia could be due to different steps involved in the preparation of the CSF sample, or more likely to the Ion Exchange Chromatographic System which we employ. The aspartic acid

TABLE II

EFFECT OF SAMPLE VOLURE ON IDENTICAL AMOUNTS OF STANDARD AMINO ACID SOLUTIONS LYOPHYLISED AND REDISSOLVED IN VARYING VOLUMES OF SAMPLE BUFFER.

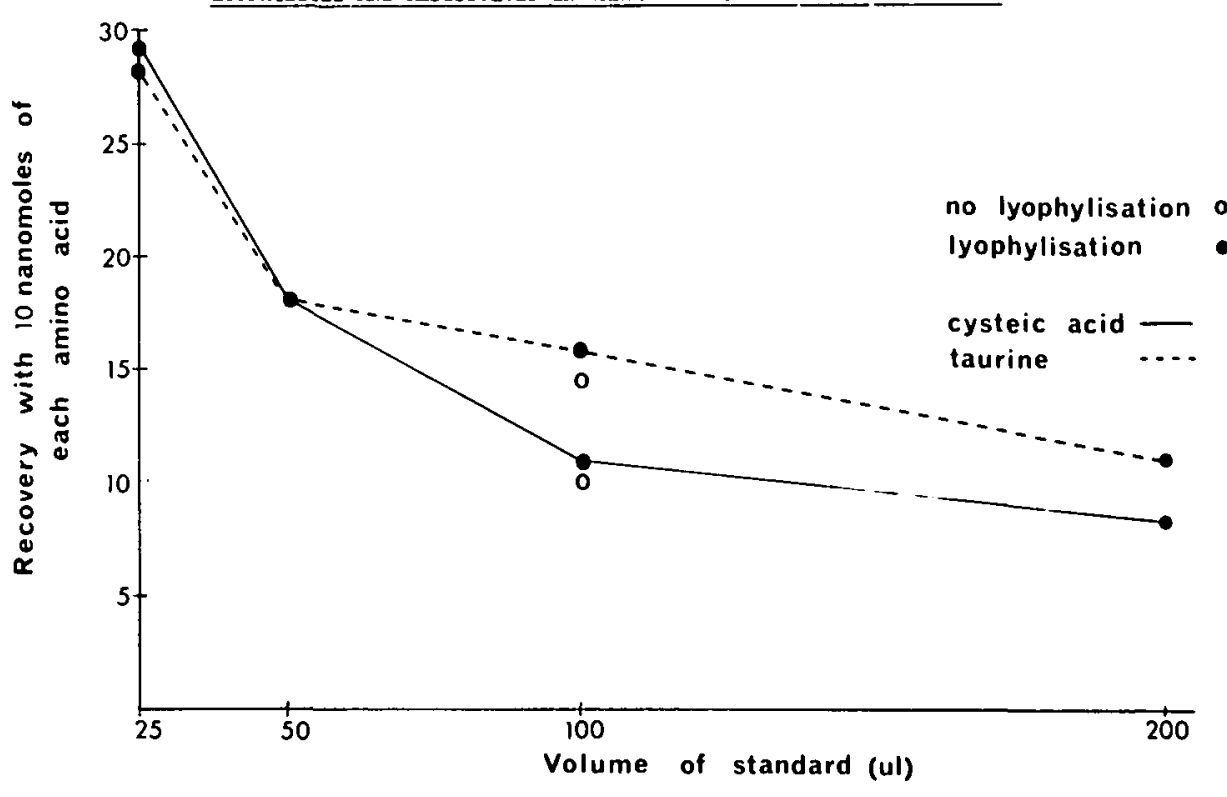

TABLE III

NEW AND ORIGINAL F.A. AND CONIROL VALUES (MEAN \pm S.D. in $\mu M D 1 / 1$ (CSF))

F.A. = Friedreich's Ataxia

AMINO ACIDS

Taurine

Aspartic Acid

Threonine

Serine

Asparagine

Glutamic Acid

Glutamine

Glycine

Alanine

Citrulline

a-Amino N-But. Ac.

valine

Cystine

Methionine

Isoleucine

Leucine

Tyrosine

Phenylalanine

Tryptophane

Ethanolamine

Ornithine

Lysine

Histidine

Homocarnosine

Arginine

\begin{tabular}{|c|c|c|}
\hline & $5 \mathrm{~F}$ & \\
\hline 0.5 & & 0.7 \\
\hline 0.7 & & 1.0 \\
\hline 16.5 & & 5.8 \\
\hline 18.0 & & 4.8 \\
\hline 2.7 & & 1.4 \\
\hline 18.3 & \pm & 21.1 \\
\hline 290.4 & \pm & 16.2 \\
\hline 4.4 & \pm & 1.7 \\
\hline 23.9 & \pm & 8.4 \\
\hline 0.4 & \pm & 0.7 \\
\hline 2.2 & \pm & 1.3 \\
\hline 14.7 & - & 2.8 \\
\hline 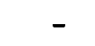 & & - \\
\hline 1 & & .0 \\
\hline 5.0 & \pm & .6 \\
\hline 17.9 & \pm & 14.8 \\
\hline 10.3 & & 5.4 \\
\hline 10.0 & \pm & 4.6 \\
\hline- & & - \\
\hline 10.4 & & 5.4 \\
\hline 3.8 & & 1.4 \\
\hline 20.4 & & 6.6 \\
\hline 10.8 & & 3.8 \\
\hline 2.4 & & 2.9 \\
\hline 18.9 & & 5.8 \\
\hline
\end{tabular}

$\mid$

\begin{aligned} & ORTGINAL CONTRO \\ & VALUES 6 SURJEC \\ & \hline $0.2 \pm 0.2 \\ & 1.9 \pm 0.8 \\ & 16.1 \pm 6.1 \\ & 20.3 \pm 9.3 \\ & 3.6 \pm 1.7 \\ & 52.0 \pm 37.5 \\ & 169.0 \pm 90.8 \\ & 5.9 \pm 2.7 \\ & 20.9 \pm 6.9 \\ & 1.0 \pm 1.0 \\ & 2.3 \pm 1.3 \\ & 14.2 \pm 4.2 \\ &-- \\ & 1.9 \pm 0.8 \\ & 0.5 \pm 1.9 \\ & 12.5 \pm 3.7 \\ & 10.4 \pm 2.4 \\ & 9.5 \pm 2.5 \\ &-- \\ & 8.6 \pm 4.5 \\ & 4.3 \pm 3.1 \\ & 13.4 \pm 3.3 \\ & 7.3 \pm 4.2 \\ & 4.4 \pm 1.8 \\ & 16.6 \pm 3.5\end{aligned}$

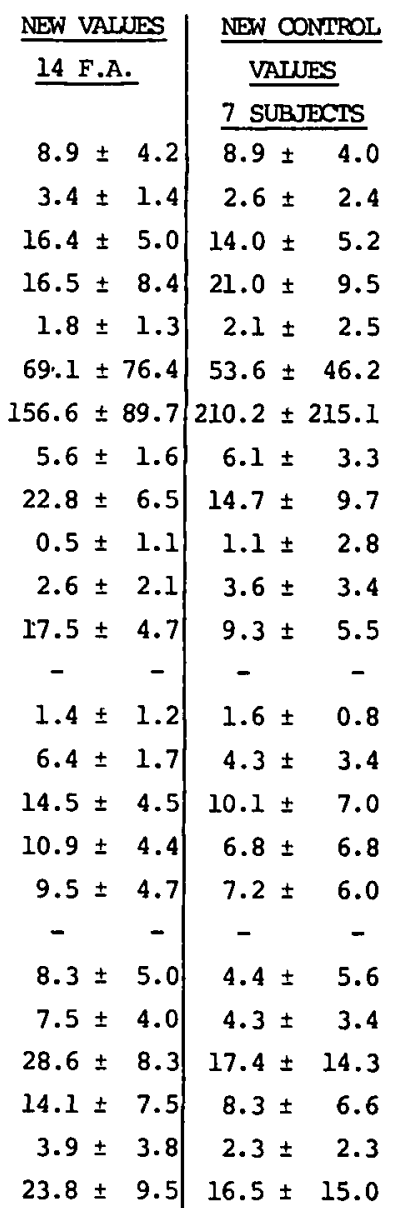


TABLE IV

TAURINE AND ASPARTIC ACID IN 14 F.A. PATIENTS AND CONIROL in $\mu$ mol/1

F.A. = Friedreich's Ataxia

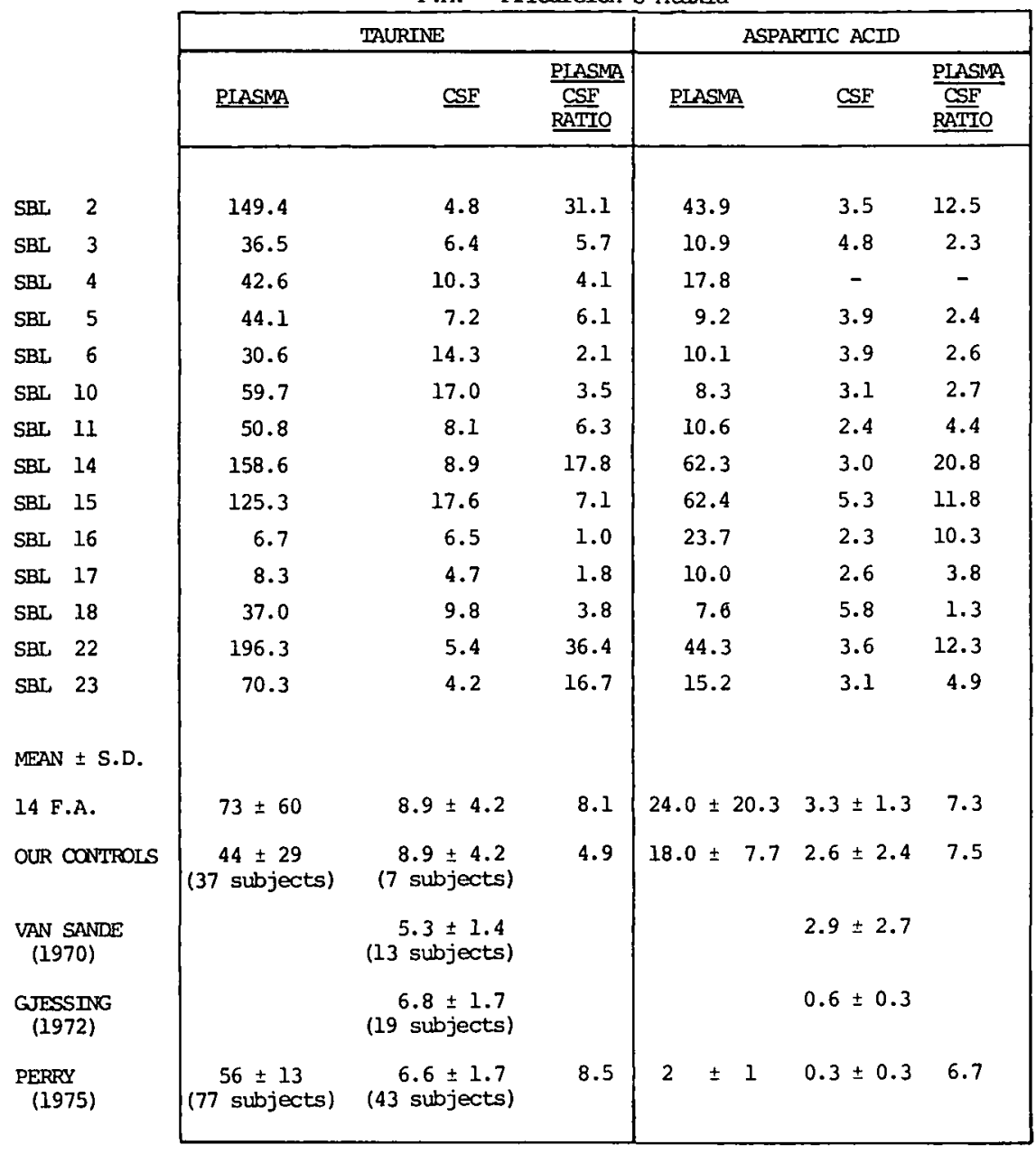

value is comparable to that reported by van Sande (1970).

\section{DISCUSSION}

Deproteinisation with different concentrations of SSA with and without lyophylisation did not alter the quantitative analysis of amino acids on Ion Exchange Chromatography. We are not aware of any report on the effect of SSA concentration and lyophylisation on the CSF proteins. As the CSF protein content is about 200 times less than the plasma protein content, there is no need to utilize more than $10 \mu-\mathrm{g} / \mathrm{ml}$ SSA. Moreover, the amount of SSA or the effect of lyophylisation should theoretically have interfered with all amino acids in the samples.

While carrying out the amino acid adsorption on the cartridge, Essner
(1976) published his data on a fast automated chromatographic method for analysis of plasma amino acids. He showed that the cartridge resin did not quantitatively retain those amino acids first eluted from the column, including cysteic acid, homocysteic acid, taurine and phosphoethanolamine, if the volume of the sample exceeded $20 \mu \mathrm{l}$. In reviewing the data of Perry and collaborators (1961, 1968, 1975), using a slow single column system, there are still some slight modifications between the values of amino acids reported and our own with the new method.

Using a fast sequential automated system (TSM), we had followed the instruction manual where it was explicitely mentioned: "upon aspiration, the sample amino acids are adsorbed on to the cartridge resin, excess fluid passing through. With the exception of cysteic acid, this adsorption is quantitative, provided that the total volume is under $0.5 \mathrm{ml}$ ". However, as we have shown here, the sample volume is critical for the efficient retention of cysteic acid and taurine, and it is evident that large volumes should not be used for CSF.

In 4 of the patients with typical Friedreich's ataxia, Dr. H. I, Yamamura of Tucson performed determinations of CSF GABA conrentrations. No significant difference was found between the levels in these patients and those in several dozen controls (personal communication).

The results shown in Tables III and IV do not substantiate a decrease or an increase of taurine or aspartic acid in the CSF of Friedreich's ataxia patients, and our previous report could have been misleading due to unsuspected technical problems. However, this difficulty does not apply to the larger volumes studied in blood and urine, where our previous conclusions stand.

\section{ACKNOWLEDGMENTS}

These studies were carried out under grants from l'Association Canadienne de l'Ataxie de Friedreich. Our sincere thanks go to Dr. H. I, Yamamura of Tucson for performing the determinations of GABA in the CSF.

\section{REFERENCES}

DICKINSON, J. C. and HAMILTON, P. B. (1966). The free amino acids of human spinal fluid determined by ion exchange chromatography. J. Neurochem., 13. 1179-1187.

ERSSER, R. S. (1976). A fast automated ion-exchange chromatographic method for the analysis of plasma acids. Med. Lab. Sci., 33, 257-263.

FISHER, R. G., PEMEROY, J. and HENRY, J. P. (1968). The free amino acids in adult human cerebrospinal fluid. Acta Neurol. Scand., 44, 619-630.

GJESSING, L. R., GJESDAHL, P. and SJAASTAD, P. (1972). The free amino acids in human cerebrospinal fluid. J. Neurochem., 19, 1807-1808.

LAKKE, J. P. W. T. and TEELKEN, A. W. (1976). Amino acids abnormalities in C.S.F. of patients with parkinsonism and extrapyramidal disorders. Neurology, 26, 489-493.

LEMIEUX, B., BARBEAU, A., BERONIADE, V., SHAPCOTT, D., BRETON, G., GEOFFROY, G. and MELAN- 
CON, S. (1976). Amino acid metabolism in Friedreich's ataxia. Can. J. Neurol. Sci., 3, 373-379.

LIAPPIS, N., JAKEL, A. and BANTLER, P. (1977). Verhalten der frein aminosauren im liquor cerebrospinalis von Kindern. Klin. Pediat., 189, 155-160.

MUTANI, R., MONACO, F., DURELLI. L. and DELSEDIME, M. (1974). Free amino acids in the cerebrospinal fluid of epileptic subjects. Epilepsia, 15: 593-597.

PERRY, T. L. and JONES, R. T. (1961). The amino acid content of human cerebrospinal fluid in normal individuals and in mental defectives. J. Clin. Invest., 40, 1363-1372.
PERRY, T. L., HANSEN, S. and KEN. NEDY, J. (1975). CSF amino acids and plasma - CSF amino acids ratios in adults. J. Neurochem., 24, 2587-2589.

PERRY, T. L., STEDMAN, D., HANSEN, $S$. and LOVE D. (1968). Homocarnosine in human cerebrospinal fluid: an age dependent phenomenon. J. Neurochem., 15, 1203-1206.

PLUM, C. M. (1974). Free amino acid levels in the cerebrospinal fluid of normal humans and their variation in cases of epilepsy and Spielmeyer - Vogt - Batten disease. J. Neurochem., 23, 595-600.
SCRIVER, C. R. and ROSENBERG, L. E. (1973). Amino acid metabolism and its disorders. In: Major Problems in Clinical Pediatrics, 10, W. B. Saunders Co., Phil., pp. 39-61.

SZILAGGYI, A. K., LAVINHA, F. and MARDENS, Y. (1974). Study of the free amino acid pattern in human cerebrospinal fluid along the cerebrospinal axis. Acta Neurol. Belg., 74, 329-336.

VAN SANDE, M., MARDENS, Y. and ADRIANNENS, K. (1970). The free amino acids in human cerebrospinal fluid. J. Neurochem., 17, 125-135. 